\title{
Microaggressions, equality, and social practices $^{1}$
}

Microaggressions are the everyday, minor and apparently innocuous 'degradations, and putdowns' experienced by members of oppressed, systematically disadvantaged or marginalised groups. $^{2}$ They are a subject of psychological research and recent campaigns, but have received little attention from political philosophers. ${ }^{3}$ Campaigns against microaggressions are also controversial, with some suggesting that those who protest take offence too easily or are oversensitive. ${ }^{4}$ Indeed the very features that define microaggressions make room for this

\footnotetext{
${ }^{1}$ With many thanks for written comments to three anonymous referees for this journal, as well as Michael Garnett, Bob Goodin, Jeff Howard, Cecile Laborde, Chaka Laguerre, Joe Mazor, Christopher Nathan, Fabian Schuppert and Katy Wells. Thanks are also due to the many audiences whose questions helped me develop these ideas, at the MSPT seminar, ANU; Nuffield Political Theory Workshop, University of Oxford; 'Empirical insights and social equality' workshop, Queen's University, Belfast; MANCEPT Workshops in Political Theory, University of Manchester; Department of Politics, University of Bristol; and Department of Politics, University of Sheffield. While writing this paper, I benefited from participation in a series of workshops on social equality funded by a British Academy/Leverhulme Trust Small Research Grant (Ref-No: SG132668) and some of the paper's research was completed under the ARC Grant on Normativity and Feasibility.

${ }^{2}$ Following Chester Pierce's definition, e.g. 'Stress analogs of racism and sexism', Mental Health, Racism and Sexism, ed. by Charles V. Willie, Patricia Perri Rieker, Bernand M. Kramer, Bertram S. Brown (University of Pittsburg
} Press,1995), pp. 277 - 293 at p. 281.

${ }^{3}$ For examples, see, 'The microaggressions project' at http://www.microaggressions.com; and psychology citations throughout. Microaggressions are also the subject of important work in critical race theory, some of which is discussed below.

${ }^{4}$ For instance, Bradley Campbell and Jason Manning, 'The new millennial 'morality': Highly sensitive and easily offended', Time, 7 November 2015, available at http://time.com/4115439/student-protests-microaggressions/; Greg Lukianoff and Jonathan Haidt, 'The coddling of the American mind', The Atlantic, September Issue 2015, available at http://www.theatlantic.com/magazine/archive/2015/09/the-coddling-of-the-american-mind/399356/. 
challenge: namely, that they are minor and seem innocuous.

One aim of this paper, then, is to give an account of what microaggressions are and what makes them objectionable. Psychologists disagree over the boundaries of the concept 'microaggression', including where the line lies between these and overt discrimination. ${ }^{5} \mathrm{I}$ offer a definition of microaggressions based on psychology, but constrained by the requirement that the concept pick out a distinctive form of injustice. The account of what makes microaggressions wrong thus helps to refine the boundary between microaggressions and other forms of discrimination. I argue that where microaggressions are an everyday experience they make a distinctive contribution to relations of oppression and marginalisation.

The paper's other aim is to demonstrate that microaggressions ought to be of greater interest to political philosophers. In particular, social or relational egalitarianism is an increasingly popular position but is often regarded as poorly defined. ${ }^{6}$ It puts having the right kinds of relationships at the heart of its theory of justice. Yet accounts of the relationships to be avoided are frequently left at an abstract level, in terms of domination, oppression and marginalisation. What kinds of relationships are desirable is often merely gestured at, with examples like citizens

\footnotetext{
${ }^{5}$ See Scott O. Lilienfeld, 'Microaggressions: Strong claims, inadequate evidence', Perspectives on Psychological Science, 12.1 (2017), 138-169. For an example of including intentional attacks, see Derald Wing Sue, Christina M. Capodilupo, Gina C. Torino, Jennifer M. Bucceri, Aisha Holder, Kevin L. Nadal, and Marta Esquilin, 'Racial microaggressions in everyday life: implications for clinical practice', American Psychologist, 62.4 (2007), 271-286.

${ }^{6}$ Jonathan Wolff labels this an 'abiding problem', in his 'Social equality and social inequality', Social Equality: On What it Means to be Equals, ed. by Carina Fourie, Fabian Schuppert, and Ivo Wallimann-Helmer (Oxford: Oxford University Press, 2015) especially at pp. 213-215. See also Carina Fourie, 'What is social equality? An analysis of status equality as a strongly egalitarian ideal', Res Publica, 18.2 (2012), 107-126, at p. 109; Fabian Schuppert on both the popularity and lack of adequate description, 'Non-domination, non-alienation and social equality: towards a republican understanding of equality', Critical Review of International Social and Political Philosophy, 18.4 (2015), 440-455,
} esp. at p. 444. 
shaking hands rather than bowing. ${ }^{7}$ Where more detail is given the focus tends to be on relations between state and citizens, rather than relations amongst citizens. ${ }^{8}$

The case of microaggressions provides a promising start to filling out what creating the right kinds of relations between citizens would involve, largely by exposing an overlooked tension amongst types of social or relational egalitarianism. It is a familiar thought that focusing on the basic structure, and so a society's major institutions, misses some of 'where the action is.' The case of microaggressions resurrects a challenge of this form with particular force for the increasing number of social or relational egalitarians who adopt such an institutional approach. Collectively, microaggressions form a social practice that is not amenable to the usual responses to a challenge of this form. Instead, shifting this social practice requires addressing, in detail, the social mechanisms that sustain it, which results in a very different approach to understanding what social equality demands than has been popular hitherto.

I begin, in section 1, with a definition of microaggressions. In sections 2 and 3, I outline what is wrong with microaggressions, defending an approach that focuses on how they collectively structure our relationships over one that sees each microaggression as a tiny

\footnotetext{
${ }^{7}$ David Miller, 'Equality and justice', Ratio, 10.3 (1997), 222-237, at p. 232. For similar examples see, 'The nature and distinctiveness of social equality: An introduction', Social Equality, ed. by Fourie et al., at pp. 2-3; Fourie 'What is social equality', at pp. 107-8, p. 112.

${ }^{8}$ E.g. Jonathan Wolff, 'Fairness, respect, and the egalitarian ethos', Philosophy \& Public Affairs, 27.2 (1998), 97-122; Martin O’Neill, 'Liberty, equality and property- owning democracy', Journal of Social Philosophy, 40.3 (2009), 379-396, especially at pp. 382-385; Christian Schemmel, 'Why relational egalitarians should care about distributions', Social Theory and Practice, 37.3 (2011), 365-390. For a similar point on the focus on the 'political or institutional level', see Social Equality, ed. by Fourie et al, at p. 4, and for this observation and another defence of attending to the social realm, see Fabian Schuppert, 'On the Range of Social Egalitarian Justice', manuscript in preparation (2017).

${ }^{9}$ G. A. Cohen, 'Where the action is: On the site of distributive justice', Philosophy \& Public Affairs, 26.1 (1997), 3-30.
} 
individual harm. In sections 4 and 5, I then defend microaggressions as a social practice that those who find relations of oppression and marginalisation objectionable must address, but one that fits uneasily with existing approaches to the site of justice.

\section{What are microaggressions?}

I start with some examples: ${ }^{10}$

Clutching your bag closer on seeing a young black man approach on the street. ${ }^{11}$

Saying, 'what are you', to enquire about someone's racial or ethnic group or asking, 'but where are you really from? ${ }^{12}$

Telling an Asian American that he or she speaks English well. ${ }^{13}$

Saying, 'cheer up love', to a woman walking down a street.

A man stating, 'what a shame', in response to learning that a woman is gay.

These acts are all microaggressions, as Chester Piece who coins the term describes: 'subtle, innocuous, preconscious, or unconscious degradations, and putdowns'. ${ }^{14}$ Pierce deploys the term to address racism, mentioning sexism, but the term is now also used to describe experiences of

\footnotetext{
${ }^{10}$ Here and throughout examples are drawn from a mix of campaigns against microaggressions and psychology.

${ }^{11}$ From Sue et al, 'Racial microaggressions in everyday life', amongst others.

${ }^{12}$ From Heben Nigatu, 'Racial microaggressions you hear on a daily basis', Burzfeed, 9 December 2013, available at http://www.buzzfeed.com/hnigatu/racial-microagressions-you-hear-on-a-daily-basis\#3x20wwe

${ }^{13}$ From Derald Wing Sue, Jennifer Bucceri, Annie I. Lin, Kevin L. Nadal, and Gina C. Torino, 'Racial microaggressions and the Asian American experience', Cultural Diversity and Ethnic Minority Psychology, 13 (2007), 7281 , at p.75.

${ }^{14}$ Pierce, 'Stress analogs of racism and sexism', at p. 281.
} 
other systemically disadvantaged and marginalised groups. ${ }^{15}$ Expanding on Pierce's definition and drawing on recent work in psychology, I propose that microaggressions are behaviours that meet the following three individually necessary and jointly sufficient conditions. ${ }^{16}$

\subsection{The conditions}

First, microaggressions are minor or subtle, such that individually the behaviours seem innocuous. ${ }^{17}$ They include particular turns of phrase, body language, comments, or tone of voice. These are often minor, consisting of little variations of body language or tone or phrasing, or, where they are not minor acts, the behaviours are still subtle so that they appear innocuous in their context, say, by being hard to detect. Their seeming innocuousness is demonstrated by some of the likely responses to microaggressions. So, the recipient of a microaggression may be

\footnotetext{
${ }^{15}$ See Pierce, ibid. For the extension to the LGBT community, see Kevin L. Nadal, Marie-Anne Issa, Jayleen Leon, Vanessa Meterko, Michelle Wideman, and Yinglee Wong, 'Sexual orientation microaggressions: “Death by a thousand cuts" for lesbian, gay, and bisexual youth', Journal of LGBT Youth, 8.3 (2011), 234-259; Kevin L. Nadal, Avy Skolnik, and Yinglee Wong, 'Interpersonal and systemic microaggressions toward transgender people: Implications for counseling', Journal of LGBT Issues in Counseling, 6.1 (2012), 55-82. For further expansions, see Microaggressions and Marginality: Manifestation, Dynamics, and Impact, ed. by Derald Wing Sue (John Wiley \& Sons, 2010), Part III. The examples in this paper focus on race, gender, and those facing the LBGT community solely since, thus far, this has been the main focus of campaigns and research.

${ }^{16}$ This paper is limited to microaggressions occurring in interactions between people, leaving aside purely environmental microaggressions.

${ }^{17}$ For a contrast to overt discrimination, with microaggressions as 'different and more subtle': Gloria Wong, Annie O. Derthick, E. J. R. David, Anne Saw, and Sumie Okazaki, 'The what, the why, and the how: A review of racial microaggressions research in psychology', Race and social problems, 6.2 (2014), 181-200, at pp. 181-2. Some might ask precisely who sees these acts as innocuous, here, I suggest that they are acts that which can pass as such to many. With thanks to an anonymous referee for raising this point.
} 
uncertain that any wrong has been committed, for instance, doubting whether some comment was meant 'that way' or whether what she experienced really happened. When the perpetrator is challenged, they may accuse the recipient of oversensitivity given the behaviour's minor nature. The perpetrator may make excuses that appeal to a lack of knowledge of the act's wrongness, or by denying that the offence was 'meant' or any wrong was done in this particular instance. ${ }^{18}$ These excuses look possible precisely because the behaviour appears innocuous.

Second, psychologists such as Derald Wing Sue and Pierce variously label microaggressions unintentional, unconscious, or preconscious. ${ }^{19}$ I suggest that the best interpretation of this condition is that to be a microaggression, the act has to be such that it is plausible that the perpetrator did not intend the act to have the effect of degrading or putting down the other. ${ }^{20}$ While some microaggressions may consist of acts that we are unaware of performing, like clasping a bag more tightly, other microaggressions may be acts we are aware of performing, such as asking the only woman in the room to take notes. That the behaviour's effects are plausibly unintentional is a central part of what makes microaggressions distinct from

\footnotetext{
${ }^{18}$ For instance, see an aeroplane case of being asked to sit at the back in Sue et al., 'Racial microaggressions in everyday life', at p. 275.

${ }^{19}$ E.g. Pierce, 'Stress analogs of racism and sexism'. See also, for the claim that microaggressions are 'not usually expressed intentionally' because the individual is unaware of his/her biases, Derald Wing Sue, Kevin L. Nadal, Christina M. Capodilupo, Annie I. Lin, Gina C. Torino, and David P. Rivera, 'Racial microaggressions against Black Americans: Implications for counseling', Journal of Counseling \& Development, 86.3 (2008), 330-338, at p. 331. For a summary of different descriptions of criteria see Wong et al., 'The what, the why, and the how', esp. pp. 182-3.

${ }^{20}$ The second condition constitutes one reason that microaggressions can seem innocuous. However, not all acts that have plausibly unintended effects are minor or subtle (say, I fling myself off a diving board, without noticing that I'll flatten an innocent swimmer below) and not all minor or subtle acts have generally or plausibly unintentional effects (consider teachers' deliberate use of particular tones of voice to control their classes). With thanks to an anonymous referee for observing the close connection between conditions (i) and (ii).
} 
overt acts of racism, sexism, homophobia, transphobia, ableism, and so on. Further, microaggressions are acts whose effects are not only plausibly unintended but usually are so. Here, then, I permit cases where microaggressions are performed intentionally, but these will be outliers. As Samantha Brennan remarks in discussing small-scale inequalities, we do not tend to intend each other such small harms. ${ }^{21}$

The third condition is that microaggressions constitute a particular kind of putdown or degradation. On the face of it, microaggressions look like a diverse or even disunified kind: they take many forms and psychologists offer varying taxonomies. ${ }^{22}$ Microaggressions may echo stereotypes about a group, for instance, asking someone who is trans whether they have had 'the' operation, or subtly demeaning individuals on the grounds of their group membership, such as telling an Asian American that she speaks English well. ${ }^{23}$ Microaggressions may highlight that an individual deviates from some norm for her group, such as telling a woman to 'cheer up', or that being a member of some group is deviating from the normal, like asking 'how can two women have sex?'. Alternatively, microaggressions might be acts that invalidate or deny the existence of oppression of, or discrimination against, a group, for instance, making a joke about the death of Michael Brown. ${ }^{24}$

So, what unites these disparate forms of putdown as microaggressions, aside from their

\footnotetext{
${ }^{21}$ Samantha Brennan, 'The moral status of micro-inequities: In favor of institutional solutions', Implicit Bias and Philosophy, Volume 2: Moral Responsibility, Structural Injustice, and Ethics, ed. by Brownstein, Michael, and Jennifer Saul (Oxford: Oxford University Press, 2016) part 3, ch.3, at section 3.

${ }^{22}$ For instance, Sue et al. distinguish micro-assaults, micro-invalidations and micro-insults, 'Racial microaggressions in everyday life'; but Nadal et al. offer twelve categories, 'Interpersonal and systemic microaggressions toward transgender people'.

${ }^{23}$ For examples like this, see Sue et al., 'Racial microaggressions and the Asian American experience', e.g., p.75.

${ }^{24}$ An example from a student's experience.
} 
seeming innocuous and being plausibly unintentional? Shortly, I defend defining microaggressions in a way that captures a particular kind of injustice. With that goal in mind, two further features serve to unify various putdowns as microaggressions. First, in paradigmatic cases, microaggressions are committed by those belonging to the dominant group with respect to the attribute to which the microaggression calls attention. ${ }^{25}$ If performed by members of the same group, acts may not be aggressions: the same action or utterance can have different meanings depending on who makes it. The suggestion here is that the functional role of microaggressions in structuring unjust relations, discussed in section 2 , is most obvious when performed by the dominant group.

Second, microaggressions can occur only towards members of subordinated groups: those that are oppressed or marginalised. Following Iris Marion Young's analysis, an oppressed group is one whose members face systemic injustice, where either structures or exercises of power by others reduce their chances or exclude them. Marginalisation is one dimension of oppression whereby some group is excluded. ${ }^{26} \mathrm{It}$ is only given that one belongs to a subordinated group that the behaviours amount to putdowns and degradations in the sense that makes them microaggressions, and only where the putdowns in question are group-based, in aiming at the subordinated facet of the person's identity. The same behaviours, insofar as there are parallels, towards members of groups not subordinate in the relevant respect — that is, the respect targeted by the behaviour — are at worst instances of discourtesy or thoughtlessness.

One might object that microaggressions can occur to anyone: everyone can face minor behaviours that unintentionally put them down. But calling these microaggressions appears to

\footnotetext{
${ }^{25}$ To illustrate, in a review of studies on racial microaggressions, Wong et al. note all are of microaggressions committed by white people, 'The what, the why, and the how'.

${ }^{26}$ Justice and the Politics of Difference (Princeton University Press, 1990).
} 
overstate the harm in a way that, as argued shortly, calling those that occur to subordinate groups does not. More importantly for my purposes, if there is a harm, it is of a different kind. To see this, consider the case of the white South African, often asked 'yes, but where are you really from?'. This does not appear to be an equivalent case, nor the same kind of injustice, as the black British person asked 'yes, but where are you really from?'. ${ }^{27}$ I take the difference here to be intuitive, but for those who disagree the following sections return to defend in detail the distinctive kind of harm of the second kind of case.

Microaggressions, then, are those minor or subtle details of interactions between people that fulfil a certain role: namely, functioning as a particular kind of degradation or putdown while appearing innocuous and plausibly unintentional. It is worth briefly noting the relationship between microaggressions and micro-inequities or implicit bias, with which philosophers may be more familiar. Implicit biases underpin some microaggressions but so, too, could explicit biases, consciously adopted stereotypes, or ignorance of a background context that makes an act problematic. Further, as Samantha Brennan notes, not all behaviours resulting from implicit bias are 'micro', such as shooting faster on seeing a black person holding an object than a white person. ${ }^{28}$ So, too, I follow Brennan in taking microaggressions to be a subset of micro-inequities — the small-scale inequities that individuals may face — including only negative behaviours. ${ }^{29}$

Microaggressions are further distinguished as a subset of micro-inequities by the particular way in which they function. So, in what follows, I consider the relational effects of microaggressions instead of any distributive effects, like not getting job interviews or good

\footnotetext{
${ }^{27}$ With thanks to Carina Fourie for this example.

28 'The moral status of micro-inequities', section 1.

${ }^{29}$ Ibid. Another more obvious difference between microaggressions and other micro-inequities is the label 'aggressions'. While some might worry about using this label for small-scale or unintentional seeming acts, I take it that it captures something about experiencing a microaggression.
} 
grades, which have been the focus in discussions of implicit bias and micro-inequities in general..$^{30}$ Sally Haslanger argued recently that focusing on implicit bias and features of individual psychology might distract us from the broader structure from which inequalities like racism and sexism arise. ${ }^{31} \mathrm{I}$ will defend microaggressions as amongst the social practices that constitute that broader structure, examining what incorporating such social practices into thinking about equality might look like.

\subsection{Defending the method}

Before that, however, the definition above faces some methodological issues. First, coming up with uncontroversial examples of microaggressions is tricky: behaviours not so obviously offensive that they fail to be microaggressions, nor so inoffensive that they fail to be microaggressions. Some might say, for example, that clutching your bag closer or asking women to take notes are instances of overt discrimination. Indeed, one interesting feature of Chester Pierce's older discussion of microaggressions is his examples. In one case, Pierce discusses a white woman so uncomfortable about sitting next to a black man on an airplane that a white man intervenes to swap seats for the sake of the woman. ${ }^{32}$ To modern sensibilities this looks instead to be a case of overt racism. Over time then we may change what instances we label microaggressions. But that changeability should give us hope, not make us think there are no such things as microaggressions. Insofar as people are unwilling to be intentionally racist, some microaggressions might be able to be tackled by altering how they are perceived.

\footnotetext{
${ }^{30}$ E.g., Jules Holroyd, 'Responsibility for implicit bias', Journal of Social Philosophy, 43.3 (2012), 274-306; Daniel Kelly and Erica Roedder, 'Racial cognition and the ethics of implicit bias', Philosophy Compass 3.3 (2008), 522-540.

${ }^{31}$ Sally Haslanger, 'Distinguished lecture: Social structure, narrative and explanation', Canadian Journal of Philosophy, 45(1) (2015), 1-15.

32 Pierce, 'Stress analogs of racism and sexism', at p. 281.
} 
Second, I deviate from some psychologists by insisting that microaggressions are minor or subtle and plausibly unintentional. Some, like Derald Wing Sue and his co-authors, have started to elide the categories of overt and unintentional by including some explicit attacks as microaggressions. ${ }^{33}$ However, there is good reason not to run the two together: namely, insisting on the plausibly unintentional and minor or subtle nature of microaggressions lets that term pick out a particular kind of injustice. ${ }^{34}$ The nature of the injustice is detailed below but, for now, consider that, in contrast to many forms of overt discrimination, it would be difficult and undesirable to legislate directly against microaggressions given the degree of intrusion into personal life that would be required to detect them.

The same desire to pick out a particular form of injustice explains a second feature of the definition. Some might object to insisting that microaggressions are by definition only performed against those belonging to oppressed or marginalised groups, in order for the act to count as a putdown of the relevant sort. Yet without that restriction the definition would fail to pick out a particular injustice, insofar as there is a difference in kind in the harm where the act targets some

\footnotetext{
${ }^{33}$ For example, for Sue and his co-authors 'micro-assaults' include intentional attacks like displaying racist symbols, 'Racial microaggressions in everyday life'. In Sue et al. micro-assaults are described as 'most similar to what has been called old-fashioned racism because their expression is deliberate, conscious, and explicit', contrasted with other unintentional forms of microaggression, 'Racial microaggressions against Black Americans', at p.330. The term is also broadened unhelpfully where psychologists include straightforward distributive inequality as microaggressions; e.g. on women being paid less, Christina M.Capodilupo, Kevin L. Nadal, Lindsay Corman, Saran Hamit, Oliver B. Lyons \& Alexa Weinberg, 'The manifestation of gender microaggressions', Microaggressions and Marginality, ed. by Derald Wing Sue, pp. 193-216.

${ }^{34}$ Indeed, Sue et al. note the very different challenges of microaggressions that are not assaults, being invisible and hard to deal with or recognise, 'Racial microaggressions against Black Americans', esp. at p. 331. Then again, Wong et al. propose instead that the 'true definition' of microaggressions is of unconscious and non-deliberate kinds rather than 'micro-assaults' simply because, as it happens, they are psychologists' focus, 'The what, the why, and the how'.
} 
marginalised or oppressed aspect of identity — a claim to which I return.

For those who disagree with such normative motives guiding a definition, this paper should be taken to concern only that large subset of microaggressions that are seemingly innocuous, plausibly unintentional, and target subordinate groups. Yet to reject the goal of delineating a normative concept that picks out a particular form of injustice requires defending some alternative approach to its analysis. Owing to the nature of the concept, it is not obvious what that alternative could be. Microaggressions are not yet an ordinary language concept. Thus, intuitions about ordinary usage are not yet a reliable guide to conceptual analysis of the term 'microaggressions', even if one holds that they are usually so.

So, too, even if there are such things as natural kinds that 'carve nature at its joints', microaggressions are an unlikely candidate. ${ }^{35}$ Some might object that the role of science is to provide us with a value-free and objective account of entities like microaggressions and that only afterwards should we proceed with normative analysis. However, the motivating interest of the investigation within psychology is precisely in investigating a particular aspect of the negative experience of oppressed or marginalised groups, and so likely involves values in carving out the phenomenon in question. ${ }^{36}$ Further, if one were to attempt to exclude values by denying that the purpose of investigating microaggressions is to examine a feature of the experiences of subordinate groups, what then would guide the definition or unify the kind? After all, microaggressions consist of a cluster of different actions with varying effects. Thus, although it may seem desirable to separate the question of how to define a microaggression from any normative analysis, in this instance to do so looks misguided.

\footnotetext{
${ }^{35}$ An often cited Platonic metaphor in debates over natural kinds.

${ }^{36}$ Indeed, Chester Pierce coins the term to capture the experience of his African-American patients, as is often remarked, e.g., Wong et al., 'The what, the why, and the how', at p. 182.
} 


\section{What's wrong with microaggressions}

Microaggressions are described as an 'everyday' experience for members of marginalised or oppressed groups: something frequently experienced throughout their lives. The examples offered range from workplaces to parties, and from acts by strangers to those by friends.$^{37}$ For this paper, I take the claim that microaggressions are everyday in this sense as an empirical assumption, but one with some support. ${ }^{38}$ So, my question is, what is wrong with microaggressions, when they are everyday? Some may be tempted to see microaggressions as merely minor irritations, even if frequent. Others may suggest that microaggressions are mere symptoms of injustice, suggesting that while it is only where societies are unjust (say, pervasively racist or sexist) that people commit microaggressions, microaggressions themselves do not contribute to the injustice. However, I argue that, when everyday, microaggressions structure and perpetuate unequal status of the kind to which egalitarians object and so are not merely a byproduct of injustice. Collectively, microaggressions form a social practice that contributes to structures of oppression and marginalisation. ${ }^{39}$

\footnotetext{
${ }^{37}$ For illustrative examples, see http://www.microaggressions.com; http://everydaysexism.com; Derald Wing Sue, Jennifer Bucceri, Annie I. Lin, Kevin L. Nadal, and Gina C. Torino, 'Racial microaggressions and the Asian American experience', Asian American Journal of Psychology, S(1) (2009), 88-101. For a comment on their widespread nature, see Sonny Nordmarken, 'Microaggressions', TSQ: Transgender Studies Quarterly, 1.1-2 (2014), 129-134, at p. 130.

${ }^{38}$ As evidence there is direct testimony from affected groups and psychological research, cited throughout. The research has shortcomings, especially, being largely qualitative. For a critical discussion, see Wong et al., 'The what, the why, and the how'. For an even more critical discussion, see Lilienfeld, 'Microaggressions', although note that the five claims he criticises are not essential to this paper's argument.

39 That microaggressions both happen and matter because of wider macro injustice is a common theme of campaigns against microaggressions, e.g. 'The microaggressions project'. It is also explored in detail within critical race theory. For illustrative examples, see Lindsay Pérez Huber and Daniel G. Solorzano, 'Visualizing everyday
} 
Not all instances of unequal status may be objectionable for egalitarians. For example, some would find ranks of managers and supervisees acceptable despite the hierarchy of status involved. But sometimes status hierarchies are objectionable. A core feature of societies that are characterised by unjust social inequalities is a ranking of people, implicitly or explicitly, as having greater or lesser standing on the grounds of characteristics like race, sexuality, gender, and the like. That form of hierarchy underpins oppression and marginalisation. So, what distinguishes the one kind of hierarchy from the other?

In brief, hierarchies of status are troubling for those who object to oppression and marginalisation at the least when the hierarchies have a unified and pervasive importance among members of society. A hierarchy has unified importance when members of the society largely share in the ranking system expressed through the hierarchy, although they may do so to varying degrees, more or less explicitly. It has pervasive importance where its way of ranking people influences one's standing across different spheres of life. These two features can be connected: a hierarchy is more likely to be pervasive where it is also unified. ${ }^{40}$

What makes a society ordered by a pervasive and unified status hierarchy troubling is that

racism: Critical race theory, visual microaggressions, and the historical image of Mexican banditry', Qualitative Inquiry, 21.3 (2015), 223-238; Lindsay Pérez Huber and Daniel G. Solorzano, 'Racial microaggressions as a tool for critical race research', Race Ethnicity and Education, 18.3 (2015), 297-320. While Wong et al., 'The what, the why, and the how', describe microaggressions as a 'specific form of oppression', this paper regards them as an injustice that supports the hierarchies underpinning oppression. Pérez Huber and Solorzano's description, discussed shortly, is closer to the account offered here.

${ }^{40}$ Some would add a further condition on when hierarchies are troubling: namely, when they do not permit much movement between different ranks, as suggested by an anonymous referee. However, when the hierarchy in status remains pervasive and unified, having someone else to take our place does not suffice to make such inequalities in status just. For instance, consider age-based status hierarchies where movement is expected. 
this kind of status follows a person across her life. ${ }^{41}$ Paradigmatic instances of oppression and marginalisation include societies ordered by precisely such unified, pervasive hierarchies of status on the basis of features such as caste, race, or gender. Further, this kind of hierarchy grounds marginalisation: to be excluded depends upon a widespread and fairly unified perception of lesser status that makes some into outsiders. More broadly, these hierarchies support oppression by underpinning the structures and exercises of power that limit some groups. As a brief illustration, being at the bottom of a status hierarchy, so being seen as lesser, can leave some less able to make themselves heard when protesting some injustice. ${ }^{42}$ Their views may be discounted owing to the standing of the group to which they belong, say, on the grounds of a stereotype that members of their group are overemotional or unreasonable. ${ }^{43}$

Microaggressions are not merely symptoms of objectionable status hierarchies but, instead, when everyday they help to structure and perpetuate these hierarchies, by partly constituting the hierarchies' pervasive and unified nature. By 'structure', I mean that the hierarchies have the form that they do partly through these small scale interactions. Lindsay Pérez Huber and Daniel Solorzano claim that 'racial microaggressions are a form of systemic,

\footnotetext{
${ }^{41}$ Then John Lucas' defence of inequality based on the plurality of hierarchies will fail, 'Against equality again', Philosophy, 52.201 (1977), 255-280. For a more detailed description, see Emily McTernan, 'The inegalitarian ethos: Incentives, respect, and self-respect', Politics, Philosophy \& Economics 12.1 (2013), 93-111. On Elizabeth Anderson’s three types of hierarchy, the status hierarchies described here combine hierarchies of standing and an aspect of hierarchies of esteem, see 'I-Expanding the egalitarian toolbox: Equality and bureaucracy', Aristotelian Society Supplementary Volume, 82 (2008), 139-160.

${ }^{42}$ See Anderson's suggestion that hierarchies of standing leave some unable to make claims, 'Expanding the egalitarian toolbox'.

${ }^{43}$ For one detailed description of epistemic injustice see Miranda Fricker, Epistemic injustice: Power and the ethics of knowing (Oxford: Oxford University Press, 2007). A detailed account of what is wrong with status hierarchies, or relations of oppression and marginalisation, lies beyond this paper's scope.
} 
everyday racism used to keep those at the racial margins in their place'. Below, I outline some of the ways that this 'keeping in place', or locating within a status hierarchy, occurs. ${ }^{44}$

First, because they are everyday, experiencing microaggressions makes one's status salient in all sorts of spheres and in all kinds of interactions. As such, microaggressions help turn an inequality between groups into a pervasive status hierarchy, rendering it the kind of unequal status that follows people across a life. Sometimes microaggressions make status salient through highlighting it or reminding people of it, such as when someone stares at a same-sex couple kissing, or tells a black person that they are 'so articulate'. ${ }^{45}$ Alternatively, they make unequal status salient through asserting it, as in making a joke that women should make the coffee or do the washing up. Making salient that feature by virtue of which, given broader social attitudes, one has a lower standing can act as a reminder of one's lesser status. ${ }^{46}$ So too, that feature may be made salient to others: to bystanders witnessing the interaction or the rest of the group of which one is a member. This last also provides a way in which microaggressions can serve to unify a status hierarchy, by reinforcing it in the minds of others.

Second, microaggressions can also make the subject of the microaggression feel like an outsider: excluded or a deviation from the perceived norm. They do so by emphasising a person's 'otherness' which marks them out as having lesser standing within a society that is racist, sexist, homophobic, transphobic, classist, ableist and so on. ${ }^{47}$ So, they can serve to express the stereotyped differences between the groups: clutching a bag closer as a young black man approaches, for example, or excessively

\footnotetext{
44 'Racial microaggressions as a tool for critical race research', at p. 302.

${ }^{45}$ For the last example: Sue et al., 'Racial microaggressions against Black Americans', at p. 331.

${ }^{46}$ Note that it need not. The context, and who is doing the highlighting, is crucial.

${ }^{47}$ For a description of microaggressions as 'othering' see Nordmarken, 'Microaggressions', at p. 129.
} 
commenting on a black woman's change of hairstyle. ${ }^{48}$ Third, microaggressions can act as reminders that members of the group are expected to confine themselves to certain roles or behaviours or be penalised. Microaggressions can be a way to police the borders of what is acceptable for a particular group, like telling a woman to 'cheer up love' if she fails to smile on the street, or making a comment that 'all Asians are good at maths'. In serving these second two functions, microaggressions contribute to the unified nature of the hierarchy by raising, and sometimes reinforcing, the purported differences between the groups. Without these purported differences the hierarchy would lose a part of its internal logic since these features are used to distinguish and separate the group.

Further, the very innocuousness of microaggressions is essential to their being able to perform these roles in perpetuating troubling status hierarchies, through contributing to the pervasiveness of the ranking system across a life. It is because they are innocuous-seeming that microaggressions are hard to detect, object to, or prevent. ${ }^{49}$ So too, it looks likely that many perform microaggressions who would not tend to be overtly or aggressively racist, sexist, homophobic or otherwise discriminatory, given they are so minor and subtle. ${ }^{50}$ That innocuousness, then, lets them spread out.

Hence, we have normative reasons to label a diverse set of phenomena 'microaggressions'. While microaggressions vary — for instance, being invalidations or

\footnotetext{
${ }^{48}$ The second example is from participants in Sue et al., 'Racial microaggressions against Black Americans'.

${ }^{49}$ E.g. Sue et al. describes the 'invisible' nature of these acts as 'preventing perpetrators from realizing and confronting' them, 'Racial microaggressions in everyday life' at p. 272. Pierce comments that microaggressions being everyday and subtle explains their power, in 'Stress analogs of racism and sexism'. See, too, on micro-inequities being innocuous and so their invisibility, Brennan 'The moral status of micro-inequities'.

${ }^{50}$ Psychologists sometimes suggest that overt forms of discrimination are in decline but these subtle forms remain, e.g., Wong et al., 'The what, the why, and the how'; Derald Wing Sue, Microaggressions in Everyday Life: Race, gender, and sexual orientation (John Wiley \& Sons, 2010), at p. xi.
} 
insults, consisting of body language or speech acts — their wrongfulness is best understood by considering them collectively. That collective impact also explains why a response to any one microaggression can easily appear an overreaction, and yet why they are objectionable. Further, it accommodates the variety in the experience of microaggressions: some microaggressions might pass unnoticed, and yet the collective practice still contributes to unequal relations. This account of the wrongfulness of microaggressions gives us reasons of justice to address acts that seem innocuous, minor, unintentional. This is a kind of injustice that distorts relations of equal standing among citizens in a particular way, being in part constitutive of, and a causal contribution to, relations of oppression and marginalisation.

\section{Defending the structural approach}

Some may disagree with characterising microaggressions in terms of their collective role in structuring unequal relations. Instead, they may be tempted to analyse microaggressions as tiny individual harms, then ask whether the perpetrator bears responsibility, especially since this is the form that the analysis of implicit bias and micro-inequities has generally taken. ${ }^{51}$ Indeed, without an account of how individual microaggressions wrong or harm people, some might dispute that any collective harm could emerge.

However, microaggressions are not unique in being apparently innocuous, individually, but collectively harmful. For example, climate change or environmental damage are partly a product of clusters of individual acts that, taken on their own, may be unobjectionable. The individual innocuousness of microaggressions, then, is not a particularly pressing objection to regarding their collective effects as harmful, any more than in the case of trivial emission-

\footnotetext{
${ }^{51}$ E.g. on tiny harms, Brennan, 'The moral status of micro-inequities'; on responsibility, Holroyd, 'Responsibility for implicit bias.'
} 
producing acts.

Still, though, one might prefer to characterise microaggressions in individual terms, as a tiny harm to relationships or a personal slight. However, then microaggressions would be experienced by those belonging to no subordinated groups too: if A makes a slightly impolite remark to B, B's relationship to A may suffer just a little or B may feel slighted, even if B faces no other disadvantage. As such, it looks like the individual account fails to pick out a particular injustice, which was the guiding aim of defining microaggressions in the first place. For those who belong to no subordinate group, the damage could not be a tiny reminder of one's lesser status owing to one's group, nor can it be a reinforcement of exclusion where one is not already marginalised. Indeed, it is doubtful that such an individual account succeeds in picking out a distinctive kind of putdown at all. All that would distinguish microaggressions is being plausibly unintentional and seemingly-innocuous and a great many cases of minor rudeness or inconsiderate behaviours fall under that description. Then, one might question the usefulness of the term 'microaggression', given that we have words enough to describe such rudenesses already.

Some might object by claiming that there is more similarity between dominant and subordinate groups than is supposed above. In particular, people can be reminded of stereotypes about dominant or privileged aspects of identity too. Take a man visiting a 'mother and baby' group where the women present make jokes about his incompetence at baby-related tasks, or boys being told to 'man up' or teased for crying. ${ }^{52}$ However, while harm may be done to men through these stereotypes and reminders, microaggressions proper function differently and in a way that results in a distinctive kind of harm. In these examples, the little reminders do not

\footnotetext{
${ }^{52}$ With thanks to Chris Bertram for the first and an anonymous referee for the second two examples, and to two referees for pushing me on the extension of microaggressions. Here, the man in the baby group case is not assumed to be a full time carer.
} 
function to put the men or boys into their lower status place qua group membership. Men are not, overall, disadvantaged by the assumption that duties to care fall on women, nor that they are the stronger gender. Instead, the reminders suggest that particular men and boys, as individuals, are failing to act in the ways deemed fitting for their higher status group. While these reminders may be harmful, then, they do not harm or act as putdowns in the same way as microaggressions proper: they do not structure relations across a life in ways that marginalise or oppress people on the basis of their group membership..$^{53}$

Regardless of the difference, one might nonetheless insist that the term 'microaggressions' ought to be extended to include slights targeting privileged aspects of identity, seeing the kind of putdown in question as somehow still sufficiently unified. Even then, though, microaggressions would become an issue of justice only collectively and against a background of marginalisation and oppression to which they contribute: only then would microaggressions change from tiny harms to a distinctive kind of injustice that patterns unjust relations. ${ }^{54}$ Thus, there remains a crucial difference between the experience of dominant groups and others, in that members of dominant groups are not wronged in the same way as are members of subordinated groups.

Thus far, however, I have ignored an alternative way to characterise microaggressions as individual harms: namely, each microaggression could be regarded as a tiny knock to an individual's self-esteem. Psychology might provide some support: after all, Chester Pierce coined the term to describe the experiences of those visiting him in

\footnotetext{
${ }^{53}$ I assume here that these examples do not stem from hierarchies of 'manliness' that are precisely akin to central cases of dominating, unified hierarchies. It seems more likely that these reminders around being the 'right' sort of man draw on hierarchies of sexism, heterosexism, and transphobia.

${ }^{54}$ See also on the whole being greater than the sum of its parts, Brennan, 'The moral status of micro-inequities'.
} 
therapy. ${ }^{55}$ Further, some hold that possessing self-esteem — or at least its background conditions - is a matter of justice. So, this version of an individualistic approach might let us say the term 'microaggressions' captures a particular injustice and a distinct kind of putdown, namely, an assault on self-esteem.

Is this self-esteem approach a viable alternative to a structural account? It might be pragmatically unwise, given that one criticism often levelled against objections to microaggressions is that people are being oversensitive. Further, picking out what counts as a microaggression by what assaults self-esteem would include a great many slights unrelated to any shared aspect of identity, as well as those targeting dominant aspects of identity. Conversely, it would exclude many experiences current labelled microaggressions, such as 'othering' microaggressions that point to a supposedly distinctive but not in itself dis-valued feature of a group (e.g., being good at maths). Finally, even were one willing to accept the pragmatic risks and the unusual scope of the definition, a problem remains. A view regarding any slight to self-esteem as an injustice is extremely demanding. The more customary approach is to claim that justice requires that all possess the social bases of self-respect. It is unclear that amongst these bases one would include the absence of ever experiencing any subtle innocuous-seeming slights of any sort.

None of the above is to deny that microaggressions could harm self-esteem. Indeed, many include equal respect as one social basis of self-respect. Thus, microaggressions might be objectionable to those egalitarians who regard the social bases of self-respect as required by justice, insofar as microaggressions perpetuate unequal respect as described in section 2. Microaggressions might even be one mechanism by

\footnotetext{
55 E.g. Pierce, 'Stress analogs of racism and sexism'. See also the suggestion that they 'sap the energy' of affected groups, Wong et al., 'The what, the why, and the how'.
} 
which possessing unequal standing has such an impact on self-respect, by reminding people of their lack.

\section{Equality and institutions}

When everyday, microaggressions contribute to injustice by structuring the status hierarchies that structure relations between citizens. That should make them of interest to political philosophers, as I argue in the remainder of this paper. For a start, as a consequence microaggressions should feature in the account of relationships among citizens required of those approaches that take social equality as their goal. In particular, the case of microaggressions demonstrates that fine-grained details of individual behaviour may contribute to status hierarchies of a kind objectionable to social/relational egalitarians. Yet microaggressions differ from the issues that have hitherto largely preoccupied such egalitarians, such as the arrangement of economic systems, welfare, laws or state bureaucracies and how these might be arranged in ways that protect people from social inequalities. ${ }^{56}$

That difference is, I suspect, a consequence of the tendency towards an institutional focus in political philosophy, exemplified by the Rawlsian emphasis on the basic structure and so on a society's major social and political institutions ${ }^{57}$ One type of relational/social egalitarian,

\footnotetext{
${ }^{56}$ On welfare, Elizabeth S. Anderson, 'What is the point of equality?', Ethics, 109.2 (1999), 287-337; Wolff, 'Fairness, respect, and the egalitarian ethos'. On redistributing or 'pre-distributing' goods see Martin O’Neill, 'Liberty, equality and property- owning democracy’ especially at pp. 382-385; Christian Schemmel, 'Why relational egalitarians should care about distributions', Alternatively, consider the list of institutional considerations in Fourie, 'What is social equality' at pp. 111-7.

${ }^{57}$ Including, for Rawls, the political constitution, legally recognised property, the economy and 'the nature of the family', Political Liberalism, (Columbia University Press, 1993) at p. 258.
} 
who I suggest we label 'social egalitarians', share that institutional approach. ${ }^{58}$ That manifests not only in which issues social egalitarians take as central, like the arrangement of the welfare system, but also in taking their theory to be directly descended from Rawls. ${ }^{59}$ The relation to Rawls is further reflected in an emphasis on securing the social bases of self-respect, which motivates a concern for equal status as one such social basis. ${ }^{60}$ In contrast, microaggressions consist of finegrained details of individual interactions. As a result, the institutionally-minded social egalitarians are likely to regard microaggressions as lying outside of the domain of justice. ${ }^{61}$ On their way of

\footnotetext{
${ }^{58}$ For the clearest examples of the type see O’Neill, 'Liberty, equality and property- owning democracy' or 'Free (and fair) markets without capitalism: Political values, principles of justice, and property-owning democracy',
} Property-Owning Democracy: Rawls and Beyond, ed. by O'Neill and Williamson (Wiley-Blackwell), pp. 75-100; Schemmel 'Why relational egalitarians should care about distributions'. Indeed, Christian Schemmel motivates relational equality by claiming that distributive theories leave out 'how institutions treat people', in 'Distributive and relational equality', Politics, Philosophy \& Economics, 11 (2012), 123-148, at p. 123; and explicitly embraces a form of social egalitarianism in 'Social equality — or just justice', Social Equality, ed. by Fourie et al.. Social egalitarian tendencies are widespread, if sometimes less explicit: see most contributions in Social Equality, ed. by Fourie et al.

${ }^{59}$ To illustrate, O’Neill claims to draw his ideal of social equality from Rawls, 'Liberty, equality and property-owning democracy', at p. 383, and in 'Free (and fair) markets without capitalism', at pp. 87-88; see also Schemmel, 'Social equality — or, just justice'. The introduction to Social Equality, suggests as one of social egalitarianism's three possible distinguishing features its offering, 'a particularly liberal egalitarian slant on recognition and domination with influence from John Rawls' 'justice-as-fairness”, ed. by Fourie et al., at p. 6.

${ }^{60}$ E.g. O’Neill, 'Liberty, equality and property-owning democracy', on status harms esp. at p.383-384; Schemmel, 'Why relational egalitarians should care about distributions.' Fourie also suggests this as one reason social equality matters, 'What is social equality' at pp. 118-9.

${ }^{61}$ Social equality's relation to justice is disputed, e.g., Miller, 'Equality and justice'; Andrew Mason, 'Justice, respect, and treating people as equals', Social Equality, ed. by Fourie et al., ch. 6. By ‘social egalitarians' I include those who regard the ideal of social equality as exhausted by what fits into an institutional approach to justice and those for whom there is more to that ideal but, regardless, say we have reasons of justice to do to only what fits. 
thinking, principles of justice should order the basic structure but not fine-grained details of behaviour within that structure, aside from citizens possessing a sense of justice. ${ }^{2}$ Further, insofar as one's desire is that citizens possess the social bases for self-respect, little slights like microaggressions look irrelevant. Instead, what matters is that all have sufficient standing overall to possess the social basis of self respect, and that might be consistent with experiencing some microaggressions.

Yet I have argued that microaggressions, if everyday, are a way in which patterns of unjust relations are structured and so perpetuated. On the face of it, those pursuing social equality should regard what sustains racism, sexism, transphobia, ableism, and the like as 'where the action is' ${ }^{63}$ Indeed, for a second kind of social/relational egalitarian, who I label 'relational egalitarians', microaggressions are easy to accommodate. Relational egalitarians also hold that justice involves the elimination of relations of oppression, marginalisation and domination, but are not committed to restricting justice to a basic structure or institutions alone. This last might be a result of a commitment to starting with existing injustices, which leaves open what counts as the primary site of justice, and of taking Iris Marion Young rather than Rawls to be the tradition's central figure. ${ }^{64}$ Further, relational egalitarians are not necessarily motivated to object to status hierarchies by a desire to secure self-respect; for instance, they may think that status hierarchies are intrinsically unjust. Relational egalitarians can thus attend to fine-grained details of

\footnotetext{
${ }^{62}$ For instance, Schemmel suggests that we 'permit inegalitarian personal attitudes in so far as they do not endanger egalitarian institutions', 'Distributive and relational equality' at p. 127. Likely, microaggressions don't threaten institutions.

${ }^{63}$ Cohen, 'Where the action is'.

${ }^{64}$ For instance, Young, Justice and the Politics of Difference; Anderson comments 'recent egalitarian writing seems strangely detached from existing egalitarian political movements','What is the point of equality' at p. 288; Wolff echoes this sort of sentiment via Sen, in 'Social equality and social inequality'.
} 
individual interactions, along with any other ways that unjust patterns emerge in social relations. ${ }^{65}$

Hence, microaggressions present a challenge to social egalitarians in particular. Social egalitarians have to explain how such fine-grained individual interactions can fit into an institutional theory of justice, or why microaggressions can justifiably be overlooked despite the way that they unjustly pattern social relations. This challenge arises precisely because by definition social egalitarians are concerned with the unjust status hierarchies to which microaggressions, if everyday, contribute. The form of this challenge is familiar: namely, that an institutional approach to justice misses out some of 'where the action is' ${ }^{66}$ Feminists make the same case with the slogan 'the personal is political'. ${ }^{67}$ Cohen does so in arguing that the difference principle, according to which social and economic inequalities are to be arranged to the 'greatest benefit of the least-advantaged members of society', should apply not only when ordering the basic structure but also to people's 'legally unconstrained' economic choices about what jobs to do or what incentives to demand..$^{68}$

Considering microaggressions might provoke parallel disputes to those arising in these

\footnotetext{
${ }^{65}$ Schemmel criticises a variant of this view, labelling it 'radical social egalitarianism', in 'Distributive and relational equality'. Fabian Schuppert is an example of this kind of relational egalitarian, with his concern with the detail of social relationships, see 'Being Equals', Social Equality, ed. by Fourie et al., ch. 5, and his 'On the range of social egalitarian justice'.

${ }^{66}$ Cohen, 'Where the action is'. My interest is not quite the standard debate over the basic structure as the primary subject of justice. Rather, I consider how an account of social equality could let something that patterns relationships — microaggressions — fall outside the domain of justice. Still, the structural similarities are helpful. ${ }^{67}$ E.g. Carol Hanisch, 'The personal is political', reprint in Radical feminism: A documentary reader, ed. by Barbara A. Crow (NYU Press, 2000), pp. 113-16. On the family and political philosophy, see Susan Moller Okin, Justice, Gender and the Family (New York: Basic Books, 1989).

${ }^{68}$ 'Where the action is'. Cohen notes the shared form with the feminist critique.
} 
other cases. So, for example, it might be observed that coercive state mechanisms or principles of justice look out of place when dealing with microaggressions, given the spheres in which they occur, just as some hold they do in family interactions, like who does more household labour. Alternatively, some may argue that worrying about microaggressions underestimates the effects of the basic structure. Following Joshua Cohen, one might hope that in a society with a just basic structure people would simply become more just. ${ }^{69}$ Others might claim that microaggressions are not where the action is, since status hierarchies would never emerge if we had ensured fair equality of opportunity, equal basic liberties, and the like. ${ }^{70}$

Raising these parallels suggests that many possible reasons for objecting to including microaggressions within the remit of political philosophy do not apply to microaggressions alone. But, more interestingly, these parallels also help to clarify the nature of the challenge to social egalitarians and, perhaps, refine a dimension of the wider debate over adopting an institutional approach. So, two natural responses to injustices apparently arising outside the domain of justice are, first, to expand that domain by adding institutions to the basic structure and, second, to rely on citizens' sense of justice. The first option is common when considering the family. The second may be tempting in instances like the gendered division of household labour or incentive-seeking, where we can understand these as choices where citizens should, or would, be guided either by the very same principles that order their society or by principles of justice appropriate for that sphere. ${ }^{71}$

\footnotetext{
${ }^{69}$ 'Taking people as they are?', Philosophy \& Public Affairs, 30.4 (2001), 363-386.

${ }^{70}$ Perhaps this is Schemmel's hope in 'Social equality — or just justice'.

${ }^{71}$ E.g., Rawls includes the family in the basic structure, Political Liberalism at p. 258; Cohen's ethos applies the difference principle to individual choices, 'Where the action is'; and Samuel Freeman points to Rawls' notion of principles of 'local justice' regulating relationships, 'The basic structure of society as the primary subject of justice', A Companion to Rawls, ed. by Jon Mandle and David A. Reidy (John Wiley \& Sons, 2013), pp. 88-111.
} 
Microaggressions fit poorly either way. We would not want to call fine grained details of individual interactions of this kind a matter of institutional arrangements, nor include all the realms of life in which they occur as belonging to a society's basic structure. Yet microaggressions are also plausibly and usually unintentional in their effects; the person clutching her bag closer does not intend to put the other down. That puts pressure on characterising the solution to microaggressions in terms of citizens choosing in accordance with principles of justice. Someone who performs a microaggression is not usually choosing to commit an injustice, nor aiming to continue relations of social inequality. Nor is it obvious that all who commit microaggressions lack a sense of justice. Someone could be fully committed to seeing people as free and equals and to supporting the just institutions, yet unwittingly commit some microaggression. Indeed, there is no reason to think that would be especially rare: a sense of justice is not likely to dictate such fine-grained details of interactions, nor need microaggressions result from any directly unjust individual attitudes, as I elaborate below. Thus, microaggressions pose a challenge for social egalitarians. On the one hand, when everyday, microaggressions contribute to a pattern of injustice by structuring relationships of unequal status. On the other, they do not fit easily within an institutional approach to justice, nor the usual ways to accommodate apparent counter-examples to that approach.

\section{Social norms and social practices}

At this point, it might be observed that the fact that racism, sexism and other forms of inequality are often perpetuated without direct intention and through 'informal' social structures ought not be surprising. ${ }^{72}$ Indeed, microaggressions are probably only one instance of a more general

\footnotetext{
${ }^{72}$ For instance, see earlier references on implicit bias. The claim here is that macro-level injustices should, in part, be tackled via considering the detail of micro-level social practices. Note the above differs to claiming that 'informal
} 
challenge faced by those social egalitarians who desire to focus on institutions and principles of justice and yet tackle structures of racism, sexism, and other forms of unjust social hierarchy. ${ }^{73}$ To conclude the paper, however, I suggest that we ought to take a piecemeal approach when dealing with the various phenomena making up these social structures.

For a start, some ways that our relations are patterned by informal social structures can be addressed through familiar means. For instance, the influence of implicit biases on distributive outcomes is amenable to correction by institutional measures. When the concern is the pattern of distribution of, say, good jobs, possible responses include affirmative action, redistributing benefits attached to jobs, or removing identity-revealing information from CVs. In contrast, what makes microaggressions problematic is how they collectively shape social relations and for that there are no equivalent institutional workarounds. Further, a central commitment among social and relational egalitarians is that relational inequalities cannot be simply addressed through the redistribution of other resources, so status hierarchies would not be so easily compensated for as, say, benefits accruing to jobs.

So, what should we do about microaggressions? Some might hope that re-characterising the sense of justice would suffice. Rather than characterising the sense of justice as applying principles of justice directly to individual choices, it could be seen as an ethos, or set of social

social structures' may be a place where social equality is also a value, as in the introduction to Social Equality., ed. by Fourie et al.

${ }^{73}$ A divide between individual/structural or institutional approaches has arisen over implicit bias, with some parallels to this discussion, e.g. Brennan, 'The moral status of micro-inequities'; Haslanger, 'Distinguished lecture'; Michael Brownstein, 'Context and the ethics of implicit bias', Implicit bias and philosophy, Volume 2, ed. by Brownstein \& Saul, part 3, ch.2. 
norms, that citizens internalise, which then pervasively shapes their behaviour. ${ }^{74}$ Perhaps that kind of ethos would operate without our having to devote attention to it on particular instances, such that we would not unintentionally engage in acts going against it, which might include microaggressions. But this hope reveals the need to attend to the details of the social phenomenon in question.

Considering the case of microaggressions suggests that sometimes social inequality is a product not of the wrong social ethos or norms but, rather, the wrong social practices. These can be distinct. ${ }^{75}$ Social practices are common patterns of behaviour within a society or subgroup. Social practices are constituted by that pattern: there is nothing more to a social practice than the pattern of behaviour persisting. In contrast, social norms being, as Elizabeth Anderson describes, 'a standard of behavior shared by a social group, commonly understood by its members as authoritative or obligatory for them', could persist, albeit in an unstable way, where the pattern of behaviour no longer does. ${ }^{76}$ So, too, in contrast to social norms, social practices need not be experienced as authoritative or obligatory by those participating in them. Further, there are social practices that are not socially enforced, where none will sanction others

\footnotetext{
${ }^{74}$ Cohen's ethos might be an example, 'Where the action is'. On the role of social norms in shaping behaviour see Emily Mc'Ternan, 'How to make citizens behave: Social psychology, liberal virtues, and social norms', Journal of Political Philosophy, 22.1 (2014), 84-104.

75 The relationship between norms and patterns of behaviour is disputed. For a discussion, see Geoffrey Brennan, Lina Eriksson, Robert E. Goodin, and Nicholas Southwood, Explaining Norms (Oxford: Oxford University Press, 2013), especially ch. 2.

76 'Beyond homo economicus: new developments in theories of social norms', Philosophy \& Public Affairs, 29 (2000), 170-200, at p. 170. Alternatively, Cristina Bicchieri describes norms as a cluster of expectations, but expectations too could unstably persist without the accompanying pattern of behaviour, see 'Norms of cooperation', Ethics 100.4
} (1990), 838-861. 
for failing to comply. ${ }^{77}$ Social practices might emerge and persist for a range of reasons, including factors of individual psychology, bias, habit or historical happenstance, as well as being underpinned by social norms.

Thus, social practices can sometimes come apart from social norms and the claim here is that microaggressions are one such example. Insofar as microaggressions are a common experience amongst members of subordinate groups, they form a social practice: a pattern of behaviour common in a society. But there is no social norm or cluster of norms directly underpinning that social practice as a whole. Those who commit microaggressions do not tend to regard themselves as meeting a 'standard of behaviour' that they understand as authoritative or obligatory for them when performing a microaggression. So, too, people do not tend to be sanctioned for refraining from committing microaggressions.

Having said that, some microaggressions are related to social norms. So, there may be subgroups within which refraining from particular microaggressions is sanctioned: imagine the member of a rugby club who refrains from any kind of political incorrectness. But microaggressions also occur in contexts without such sanctioning. So, too, some microaggressions reflect norms that the perpetrator has internalised about the group in question's behaviour, say that women ought to be, and are expected to be, pleasant. ${ }^{78}$ But not all microaggressions are so clearly tied to particular social norms about appropriate behaviour for individuals.

Further, despite such relations, the distinctness of a social practice as compared to a social norm has practical significance in the case of microaggressions. As a consequence,

\footnotetext{
${ }^{77}$ Some prefer a definition of social norms focused on sanctions. For a discussion of the disagreement over defining social norms see Social Norms, ed. by Michael Hechter and Karl-Dieter Opp (Russell Sage Foundation, 2001), at pp. xi-xx.

${ }^{78}$ With thanks to an anonymous referee for this observation and helpful example.
} 
correcting this social practice might not, or not only, require ensuring that we have a sense of justice or anti-discriminatory social norms, since these are not the only factors that produce the social practice in question. For example, we might need to alter associated social norms that, while they do not make some microaggression obligatory for us or lead us to sanction those who fail to put down others, nonetheless result in microaggressions. These will include some norms of politeness. Recall the aeroplane example earlier, where a white man gets up and swaps seats since a white woman looks uncomfortable sitting next to a black man. Now, I take it, this behaviour appears rude (as well as racist). But then, perhaps, it might have been construed by the white man as polite, attending to the comfort of the woman. Alternatively, as another example, education might be required, for instance, on the correct terminology to use when discussing someone's identity or the particular background context and historical injustices that, say, make commenting on a black woman's hair a microaggression.

Thus, here I echo Lawrence Lessig's criticism of the treatment of social norms within law and economics as a kind of 'blob' to be pushed from all sides, without paying attention to the detail of particular cases. To undermine bad social norms, Lessig suggests, we have to address the particular social meanings and social roles involved. ${ }^{79}$ I suggest that similar attention to detail would be required to shift social practices like microaggressions and so secure social equality. Not only that, but how to do so likely varies across differing microaggressions depending on their particular and varying roots in social norms, historical context, among other factors. ${ }^{80}$ As such, taking the nature of social practices seriously also has normative implications. In particular, insofar as microaggressions structure relationships of the kind egalitarians find objectionable, being oppressive or marginalising, they must attend to fine-grained features of our interactions.

\footnotetext{
79 'Social meaning and social norms', University of Pennsylvania Law Review ,144.5 (1996), 2181-2189.

${ }^{80}$ Thus, the causal story offered for microaggressions here is a partial and limited one, precisely because it will depend very much on fine details. With thanks to an anonymous referee for pushing me on this point.
} 
They cannot instead rely on general appeals to the side effects of having the right institutions or a sense of justice to do the work: these institutional strategies may well leave the phenomenon of microaggressions largely intact. Hence, relational and social egalitarian accounts of what relations of social equality look like and how we could secure them will be costly to construct, requiring a wealth of details about how our social interactions are structured and maintained. Further, providing these details will no doubt give rise to a series of particular normative issues that will have to be addressed, including, for instance, how to balance the demands of achieving social equality against concerns about excessive intervention in people's lives, or whether one can permissibly seek to undermine social norms that only indirectly contribute to microaggressions.

So, to conclude, the goal of this paper has not been to answer how to end microaggressions. Instead, it has been to argue that microaggressions are both an injustice and an interesting case for political philosophers. In particular, the case of microaggressions suggests that social practices are amongst the phenomena that we should think about when we are concerned with justice, not only institutions and individual choices. Social practices, too, can structure and pattern our relationships in ways that can be unjust. Considering microaggressions, then, presses home that the social realm is a site of justice — or, at least, injustice — for any account that makes the heart of justice a matter of having the right kinds of relations among citizens.

However, the case of microaggressions also suggests that accommodating the social realm within an account of justice will not be straightforward. Addressing social injustices, where phenomena like microaggressions pattern relationships among citizens, requires engaging with the details of social interactions and their underlying mechanisms. This paper tackles only a very small part of that task. Considering this kind of detail is an unfamiliar task for many political philosophers, surprisingly, even for social egalitarians with their claims to be centrally concerned with the nature of our relationships. But it ought not be. 